\title{
Regarding the Glasgow Blatchford scale
}

\section{Respecto a la escala de Glasgow Blatchford}

\author{
Ana G. Beraun Cruz, Dayanna A. Figueroa-Pecho and Pedro J. Chunga-Tume* \\ Professional School of Human Medicine, Universidad Privada San Juan Bautista, Chorrillos, Lima, Peru
}

The work carried out by Olivarec et al. evaluated the ability of the Glasgow Blatchford score (GBS) to identify the risk of re-bleeding 30 days after upper gastrointestinal bleeding, and it was found to be useful; however, there is literature that contradicts this study. ${ }^{1}$

Chang et al., on the contrary, demonstrate the importance of GBS for predicting mortality, need for blood transfusion and the need for endoscopic intervention; however, it is not useful for predicting the risk of re-bleeding, given that, in the study by Olivarec et al., they exclude the presentation characteristic parameter and comorbidities, in contrast to this study. ${ }^{2}$

Stanley et al. found that the Progetto Nazionale Emorrhagia Digestiva (PNED) score is superior to GBS for re-bleeding, due to the usefulness of re-bleeding and endoscopy within its score; in addition it predicted 7-day re-bleeding; however they conclude that no system predicts re-bleeding risk. ${ }^{3}$

Concurrently, Chandnani et al. conclude that PNED is better for evaluating re-bleeding in comparison with GBS, but when modified PNED (it does not include re-bleeding in its score) and GBS were compared, both had the same performance. ${ }^{4}$

Similarly, Lu et al., who compared GBS and the Rockall score (RS), which also uses endoscopy, when omitting this parameter (pre-endoscopic RS), found out that it is still better for predicting re-bleeding. ${ }^{5}$

Therefore, we must consider the use of other scales such as the above-mentioned for re-bleeding risk in order to prevent it and provide timely treatment.

\section{Funding}

The authors declare that they have not received any funding for this work.

\section{Conflict of interests}

The authors declare that they have no conflicts of interest.

\section{Ethical disclosures}

Protection of human and animal subjects. The authors declare that no experiments were performed on humans or animals for this research.

Confidentiality of data. The authors declare that they have followed the protocols of their work center on the publication of patient data.

Right to privacy and informed consent. The authors declare that no patient data appear in this article.

\section{References}

1. Olivarec-Bonilla M, Herrera-Arellano AMGA. Riesgo de resangrado en hemorragia digestiva alta según la escala de Glasgow-Blatchford: herramienta de triage. Gac Med Mex. 2020;156:502-8.

2. Chang A, Ouejiaraphant C, Akarapatima K, Rattanasupa A, Prachayakul V. Prospective comparison of the AIMS65 score, Glasgow-Blatchford score, and Rockall score for predicting clinical outcomes in patients with variceal and nonvariceal upper gastrointestinal bleeding. Clin Endosc. 2021;54(2):211-21.

3. Stanley AJ, Laine L, Dalton HR, Ngu JH, Schultz M, Abazi R, et al. Comparison of risk scoring systems for patients presenting with upper gastrointestinal bleeding: International multicentre prospective study. BMJ. 2017;356:1-8.

4. Chandnani S, Rathi P, Sonthalia N, Udgirkar S, Jain S, Contractor Q, et al. Comparison of risk scores in upper gastrointestinal bleeding in western India: A prospective analysis. Indian J Gastroenterol. 2019;38(2):117-27.

5. Lu M, Sun G, Huang H, Zhang X, Xu Y, Chen S, et al. Comparison of the Glasgow-Blatchford and Rockall scores for prediction of nonvariceal upper gastrointestinal bleeding outcomes in Chinese patients. Med (United States). 2019;98(21):1-5.

\section{Correspondence:}

*Pedro J Chunga-Tume

E-mail: pedro.chunga@upsjb.edu.pe
Gac Med Mex. 2021;157:553

Contents available at PubMed

www.gacetamedicademexico.com

0016-3813/@ 2021 Academia Nacional de Medicina de México, A.C.. Published by Permanyer. This is an open access article under the CC BY-NC-ND license (http://creativecommons.org/licenses/by-nc-nd/4.0/). 